\title{
Low COVID-19-related practice increases the risk of poor health literacy in international students
}

\author{
Nergiz Sevinc $^{{ }^{*}}$ and Burcu Korkut ${ }^{2}$
}

ABSTRACT
BACKGROUND
Health literacy (HL) is the ability to access, understand, appraise, and
apply health information, making it crucial for navigating coronavirus and
COVID-19 information environments. The objective of this study was to
determine the health literacy of international students who could not return
to their countries after announcement of the coronavirus disease (COVID-
19) pandemic and their perspective and behavior about COVID-19.

\section{METHODS}

A cross-sectional study was conducted involving 399 international students. A 73-item questionnaire consisting of health literacy (23 items), knowledge, attitude and practice about Covid-19 (37 items), and sociodemographic characteristics (13 items) was answered by the students. The relationship between the HL score and various variables was determined using univariate and multiple binary logistic regression.

\section{RESULTS}

Of the 399 international students, 322 (80.7\%) participated. The HL of the international students was found to be poor (78.0\%) and good $(22.0 \%)$. Participants' COVID-19-related behaviors: $8.4 \%$ of the participants' knowledge level was good, and 38.5\% had high COVID-19 related practice. Multivariate models showed that HL was independently and significantly associated with COVID-19 related practice $(\mathrm{OR}=6.27$; 95\% CI: 2.45 - 15.79; $\mathrm{p}=0.000)$.

\section{CONCLUSION}

This study revealed that international students' HL was poor and that low COVID-19 related practice increased the risk of low HL in international students. According to the findings, further efforts should be made to enhance levels of HL and COVID-19-related behavior of international students.
${ }^{1}$ Department of Public Health, School of Medicine, Karabük University, Turkey

${ }^{2}$ Karabük Public Health Directorate

\section{Correspondence:}

*Nergiz Sevinc Karabuk University Faculty of Medicine, Baliklar Kayasi Mevkii, Demir Çelik Campus,

Karabuk, Turkey.

Email: dr.nergizsevinc@gmail.com; phone: +905468211834 ORCID ID: 0000-0003-4763-1902

Date of first submission, February 25, 2021

Date of final revised submission, April 22, 2021

Date of acceptance, May 4, 2021

This open access article is distributed under a Creative Commons AttributionNon Commercial-Share Alike 4.0 International License

Cite this article as: Servic N, Korkut B. Low COVID-19-related practice increases the risk of poor health literacy in international students. Univ Med 2021;40:79-86. doi: $10.18051 /$ UnivMed.2021.v40.79-86

Keywords : International student, health literacy, COVID-19, behavior 


\section{INTRODUCTION}

The novel human coronavirus disease (COVID-19) first emerged in Wuhan city of China and then spread all over the world, becoming a global public health problem. ${ }^{(1-4)}$ The World Health Organization (WHO) reported that about 15 million people were infected with COVID-19 by July 2020, and 620 thousand people died. ${ }^{(5)}$ The number of cases has now exceeded 15 million showing how quickly the virus spreads considering the lower number of cases reported in previous studies. ${ }^{(6,7)}$ Soon after the COVID-19 outbreak turned into a pandemic, the WHO warned all the countries regarding the required measures to decelerate the spread of the virus and to minimize the possible risks. ${ }^{(8)}$ The measures taken such as travel restriction, quarantine and social distancing have caused the individuals to have psychological problems and reduced quality of life. ${ }^{(9-12)}$ Following the first death case in China, passengers were screened with thermal cameras at airports in Turkey, flights to China were canceled, the Iran border gates were closed, and flights to Italy and South Korea were canceled. After the first coronavirus case was confirmed on 11 March 2020 in Turkey, some restrictions were imposed gradually to prevent and minimize the spread of the virus across the country. Data received by the Turkish Ministry of Health on October 25, 2020, showed that nationally 362.800 were positive, 163.093 recovered, and 9.799 died. $^{(13)}$

Health literacy (HL) is the use of a wide range of skills including reading, writing, speaking, listening, numeracy, critical analysis and communication in order to improve an individual's ability to act on knowledge to lead healthier lives. ${ }^{(14)}$ The effects of socio-economic factors such as age, gender, and economic status on the level of health literacy have been known for a long time. ${ }^{(15)}$ Today, low HL is accepted as an important determinant of morbidity and mortality among the elderly in many developed countries. ${ }^{(16)}$ Besides age, low income and language problems can have a negative impact on health literacy. In a study evaluating immigrants' HL, researchers found that immigrants with language problems have lower levels of HL. ${ }^{(17)}$ In a recent study, it was found that people with poor literacy skills have low health behavior. ${ }^{(18)}$ Given that HL plays a key role in the ability of individuals to correctly understand information and warnings on health as well as properly use the information that they have obtained, HL has become a defining concept for the countries in tackling the outbreak. ${ }^{(19,20)}$ Improving the HL level of society by following the public health guidelines will obviously play an important role in tackling the COVID-19 pandemic.

While the countries sending students abroad for higher education have preferred Western countries for many years, in recent years a growing number of international students have opted for Turkey. The number of international students studying in Turkey in the last decade has risen from 15893 students to 125138 students in 2018. (21) During the COVID-19 pandemic, the responsibilities and roles of the international students are determined by the campus committees in line with the recommendations of the Turkish Ministry of Health. Hand-washing, wearing masks, keeping a safe distance and awareness of quarantine and self-isolation are defined as their main responsibilities. ${ }^{(22)}$ Although many studies have been conducted to investigate the HL levels in different age and occupation segments of the community within a very short period since the first day of the COVID-19 outbreak, there are only a small number of studies which have explored the HL levels of university students on COVID-19. A study investigating the levels of health literacy among Pakistani university students in the COVID-19 pandemic and infodemic revealed that their HL was not at an optimal level as these participants expressed difficulty for half of the items of the health literacy scale. (23) Another study showed different results, in that medical students had better knowledge $(41.8 \%$ vs $33.2 \%$, p- 
value $=0.000)$ and health protocol compliance ( $6.3 \%$ vs $2.4 \%$, p-value $=0.049)$ than non-medical students. ${ }^{(24)}$ In a study conducted in Indonesia on the COVID-19 HL level of biology teacher candidate students, it was determined that most of the students did not have sufficient knowledge about COVID-19 symptoms, routes of transmission and the role of vaccines, and it was also suggested to provide these students with comprehensive education about COVID-19. ${ }^{(25)}$ Similarly, in a study conducted on medical students, the relationship between the level of HL and fear of COVID-19 was investigated. The results of the study revealed that HL showed a protective effect on fear and that smoking and drinking appeared to have a negative effect on fear of COVID-19. ${ }^{(26)}$ However, no study has been conducted so far on international students. The present study aimed to determine the behavior on COVID-19 and the HL level of international students who were studying in Karabük University and who could not return to their countries due to the outbreak.

\section{METHODS}

\section{Research design}

This cross-sectional study was conducted between May and August 2020 on international students studying in Karabük University who could not return to their countries due to the COVID-19 outbreak.

\section{Study subjects}

A total of 399 international students were recruited into the study. They were informed about the study before the administration of the questionnaire and the participants were chosen among those who had been living in Turkey for at least 2 years. However, 26 students who gave incomplete answers to questions and 51 students who refused to participate in the study were excluded from the study. Verbal informed consent was obtained from the participants before data collection. Prior to the interview, participants and interviewers washed their hands. Participants and interviewers wore face masks and did not make any physical contact with each other. Paper and pens were not shared among the participants. In observance of the social distancing rules, the interview was conducted outdoors, with the participants seated at least 2 meters from each other. A face-toface survey was administered to 322 students who agreed to participate in the study after receiving their verbal consent.

\section{Measurements}

The questionnaire was prepared based on published literature and information available on the websites of the WHO. ${ }^{(5,27-29)}$ The questionnaire was initially structured in English. It was reviewed by public health experts (two associate professors and three assistant professors) and revised according to their recommendations. Thereafter the questionnaire was translated into Turkish. The data collection form consisted of a total of 73 questions. The first part contained 13 questions about sociodemographic characteristics such as age, sex, nationality, economic situation and accommodation. The second part contained 37 yes-no questions. To evaluate knowledge on COVID-19, 15 questions were prepared. The participants were asked about symptoms, risk factors, transmission routes, vaccination and treatment of COVID-19. To determine the behavior of the participants, 12 questions were prepared about how to protect oneself against coronavirus. A score of 1 was assigned for a correct answer and 0 for a wrong answer for knowledge and practice questions, with a total possible knowledge score of $0-15$. In accordance with a similar study, level of knowledge was categorized into "low" for participants who scored $<10$, and "high" for those who scored $>10 .{ }^{(27)}$ As to the scoring of practice, the total possible score was 0-12 and participants with scores of $<9$ and $>9$ were considered to have "low" and "high" practice, respectively. To assess attitudes toward COVID-19, the participants were asked 5 questions including 
statements on the sources of information about the coronavirus, whether it may be a fatal disease and whether the disease was exaggerated or not. Each positive attitude received 1 point, with a total possible attitude score of $0-5$; participants with a score $<3$ and $3>$ were considered to have "low" and "high" attitude, respectively.

The third part, adult health literacy scale (AHLS), consisted of a health literacy questionnaire with 23 questions. The AHLS developed by Sezer et al., ${ }^{(29)}$ the reliability and validity of which had been tested, consists of 1 diagram and questions about health information and drug use to determine the competency of adult individuals in HL. Thirteen of the questions were yes/no questions, 4 were gap-filling questions, 4 were multiple-choice questions and 2 were matching questions. Each question was individually scored. Those who marked the positive expressions in the yes/no questions were given 1 point, those who marked the negative expressions were given 0 point, those who marked the correct answer in the gap-filling questions were given 1 point, and those who marked the wrong answer were given 0 point. Those who marked two or more correct answers in the multiple-choice questions were given 1 point, and those who marked no correct answer or both correct and wrong answers were given 0 point. Those who matched more than two correct answers in the matching questions were given 1 point, and the others were given 0 point. As a result of reliability and validity analysis, the reported Cronbach alpha coefficient of AHLS was found to be 0.77 and the test-retest reliability coefficient was found to be 0.87 . The content validity index of AHLS that consists of 23 items was found to be $90.71 \%$. Although the cutoff score of the scale was not calculated, it was considered that the higher scores in the questionnaire were deemed to indicate a higher level of health literacy. With a total AHLS score of 0-23, participants with scores of 0-11 and 12-23 were considered to have poor and good $\mathrm{HL}$, respectively. Based on these findings, Sezer et al. ${ }^{(29)}$ suggested that the AHLS is reliable and can be used in the adult group.

\section{Statistical analysis}

The data were evaluated in a computer environment using SPSS package software version 22.0. The categorical data were expressed as frequency and percentage distribution.

Knowledge, practice and attitude scores were categorized into low and high. The relationship of HL with socio-demographic and further characteristics was tested by univariate and multiple logistic regression analysis. The $\mathrm{p}$ values $<0.05$ were considered statistically significant.

\section{Ethical clearance}

The ethics committee approval (No. 2020/ 230) was obtained from Karabük University and permission was also obtained from the Ministry of Health.

\section{RESULTS}

Three hundred twenty-two international students were included in the study; $85.1 \%$ of them were male, while $14.9 \%$ were female, and the median age was $22.0 .68 .3 \%$ of them were African, while $31.7 \%$ were Asian. $92.9 \%$ of the participants were single, $59.3 \%$ had been living in Turkey for at least 2 years, and $39.1 \%$ had been studying in engineering. Because of the pandemic $65.5 \%$ of them had to stay in Turkey, and $77.3 \%$ of them had been living at residence during the pandemic. Also, $77.6 \%$ of the participants had not received any previous health training (Table 1).

As for the behaviors of the international students related to COVID-19, $91.6 \%$ of the participants had a low knowledge level, $61.5 \%$ had a low level of practice and $66.1 \%$ had low level of attitude.

With regard to the HL score of the international students, $78.0 \%$ was found to have poor HL and $22.0 \%$ good HL. The results of 
Table 1. Characteristics of the participants $(n=322)$

\begin{tabular}{lc}
\hline Characteristics & $\mathbf{n}(\mathbf{\%})$ \\
\hline Age (years) & $245(76.1)$ \\
$18-24$ & $77(23.9)$ \\
$\geq 25$ & $48(14.9)$ \\
Sex & $274(85.1)$ \\
Female & \\
Male & $122(37.9)$ \\
Economic status & $190(59.0)$ \\
Good & $10(3.1)$ \\
Moderate & \\
Bad & $191(59.3)$ \\
Duration of living in Turkey (years) & $106(32.9)$ \\
2 & $25(7.8)$ \\
3 & \\
$\geq 4$ & $72(22.4)$ \\
Have you received a training on health? & $250(77.6)$ \\
Yes & \\
No & $295(91.6)$ \\
Knowledge & $27(8.4)$ \\
Low & \\
High & $213(66.1))$ \\
Attitude & $109(33.9)$ \\
Low & \\
High & $208(66.1)$ \\
Practice & $124(38.5)$ \\
Low & \\
High & $251(78.0)$ \\
Health literacy & $71(22.0)$ \\
Poor & \\
Good & \\
\hline
\end{tabular}

bivariate logistic regression analysis showed that duration of living in Turkey and receiving training on health and knowledge on COVID-19 were not significantly associated with $\mathrm{HL}$, but that attitude and practice on COVID-19 were significantly associated with HL (Table 2). The multivariate logistic regression showed that practice was the risk factor of HL among international students. Low levels of COVID19-related practice will increase the risk of low HL $(\mathrm{OR}=6.27 ; 95 \% \mathrm{CI}: 2.45-15.79 ; \mathrm{p}=0.000)$ (Table 2).

\section{DISCUSSION}

The present study was focused on HL and the related behavior including knowledge, attitude and practice on COVID-19 of the international students who have studied in Karabuk University, Turkey. Findings from this study revealed that the HL scores of the international students were low, and their COVID-19-related knowledge and practices were also low. In our study the attitude and practice about COVID-19 were associated significantly with HL. This result was in line with the study among 256 students in the US showing that HL was independently associated with preventive practices about COVID-19.(30) Students with lower HL use social media more frequently and thus are at greater risk of exposure to false and misleading information, possibly becoming additional vectors in the propagation of poor information, encouragement of harmful health practices, or resistance to public health guidance. 
Table 2. Bivariate and multiple binary logistic regression of socio-demographic and further characteristics with health literacy $(n=322)$

\begin{tabular}{|c|c|c|c|c|c|c|}
\hline \multirow{2}{*}{ Characteristics } & \multicolumn{3}{|c|}{ Bivariate logistic regression } & \multicolumn{3}{|c|}{ Multiple logistic regression } \\
\hline & $\mathbf{O R}$ & $95 \% \mathrm{CI}$ & p value & $\mathbf{O R}$ & $95 \% \mathrm{CI}$ & p value \\
\hline \multicolumn{7}{|l|}{ Age (years) } \\
\hline $18-24$ & 1 & & & 1 & & \\
\hline$\geq 25$ & 6.86 & $2.41-19.53$ & 0.000 & 11.75 & $3.08-44.75$ & 0.000 \\
\hline \multicolumn{7}{|l|}{$\operatorname{Sex}$} \\
\hline Female & 1 & & & 1 & & \\
\hline Male & 0.20 & $0.06-0.67$ & 0.009 & 0.29 & $0.07-1.10$ & 0.070 \\
\hline \multicolumn{7}{|l|}{ Economic status } \\
\hline Low & 1 & & & 1 & & \\
\hline High & 0.32 & $0.18-0.55$ & 0.000 & 0.20 & $0.08-0.51$ & 0.001 \\
\hline \multicolumn{7}{|l|}{$\begin{array}{l}\text { Duration of living in Turkey } \\
\text { (years) }\end{array}$} \\
\hline 2 & 1 & & & 1 & & \\
\hline $3 \geq$ & 0.68 & $0.39-1.19$ & 0.183 & 0.45 & $0.19-1.04$ & 0.063 \\
\hline \multicolumn{7}{|c|}{$\begin{array}{l}\text { Have you received a training on } \\
\text { health? }\end{array}$} \\
\hline No & 1 & & & 1 & & \\
\hline Yes & 0.73 & $0.39-1.34$ & 0.315 & 0.50 & $0.21-1.17$ & 0.112 \\
\hline \multicolumn{7}{|l|}{ Knowledge } \\
\hline Low & 1 & & & 1 & & \\
\hline High & 0.79 & $0.32-1.95$ & 0.612 & 0.78 & $0.27-2.22$ & 0.645 \\
\hline \multicolumn{7}{|l|}{ Attitude } \\
\hline Low & 1 & & & 1 & & \\
\hline High & 0.43 & $0.25-0.73$ & 0.002 & 0.14 & $0.06-0.33$ & 0.000 \\
\hline \multicolumn{7}{|l|}{ Practice } \\
\hline Low & 1 & & & 1 & & \\
\hline High & 1.96 & $1.10-3.52$ & 0.023 & 6.27 & $2.49-15.79$ & 0.000 \\
\hline
\end{tabular}

threaten public health, such as pandemics. ${ }^{(34,35)}$ According to Paakkari, ${ }^{(6)}$ health literacy should be seen in relation to social responsibility and solidarity. In a study evaluating the relationship between the level of HL and the level of fear of COVID-19, health literacy was found to protect medical students from fear, ${ }^{(26)}$ while Sun et al. found that health literacy is a direct influencing factor of health behavior. ${ }^{(36)}$

In our study, the HL levels were poor. Fauzi et al. (26) conducted a study on 290 biology teacher candidate university students and reported that most of the students had a poor level of HL. The fact that the COVID-19 related practices of the students were inadequate may be associated with the poor HL level. Universities and public institutions can provide information via electronic boards, announcement posters and e-mails so that these students can access reliable information sources in pandemic situations and overcome the negative effects of the pandemic.

There are some limitations of the study. The first limitation is the lack of an outbreak-specific HL scale as the study was conducted at the beginning of the pandemic. The second limitation is that most of the participants were male $(85.1 \%)$ due to the unwillingness of female students to participate in the study. Therefore, the results of this study cannot be generalized since it is a single-center study and male participation is higher than female participation. Moreover, the researchers did not analyze any potential moderating effect or association between the field of study and HL. Further research must be done in several centers with a better design such as a cohort study. 


\section{CONCLUSION}

The HL of international students was poor. In addition, their low COVID-19-related practices will increase the risk of poor HL among international students. Continuing public and professional education campaigns about COVID-19 should be expanded to include international students.

\section{CONFLICT OF INTEREST}

None declared.

\section{CONTRIBUTORS}

NS contributed to writing the original draft. NS and BK contributed to review and editing. NS and BK contributed to data collection and analysis. Both authors have read and approved the final manuscript.

\section{REFERENCES}

1. Ren LL, Wang YM, Wu ZQ, et al. Identification of a novel coronavirus causing severe pneumonia in human: a descriptive study. Chinese Med J 2020;133:1015-24. doi: 10.1097/ CM9.0000000000000722.

2. Wang C, Horby P, Hayden FG, et al. A novel coronavirus outbreak of global health concern. The Lancet 2020;395:470-3. https://doi.org/ 10.1016/S0140-6736(20)30185-9.

3. Wu JT, Leung K, Leung GM. Nowcasting and forecasting the potential domestic and international spread of the 2019-nCoV outbreak originating in Wuhan, China: a modelling study. The Lancet 2020;395:689-97. https://doi.org/ 10.1016/S0140-6736(20)30260-9.

4. World Health Organization (WHO). Statement on the Second Meeting of the International Health Regulations (2005) Emergency Committee Regarding the Outbreak of Novel Coronavirus (2019-nCoV) 2020. Geneva: World Health Organization;2020.

5. World Health Organization (WHO). DirectorGeneral's opening remarks at the media briefing on COVID-19-23 July 2020. Geneva: World Health Organization;2020.
6. Paakkari L, Okan O. COVID-19: health literacy is an underestimated problem. Lancet Public Health 2020;5:e249-50. doi: 10.1016/S2468-2667(20)300864.

7. Zarocostas J. How to fight an infodemic. The Lancet 2020; 395: 676. doi: 10.1016/S01406736(20)30461-X.

8. Wolf MS, Serper M, Opsasnick L, et al. Awareness, attitudes, and actions related to COVID-19 among adults with chronic conditions at the onset of the US outbreak: a cross-sectional survey. Ann Intern Med 2020; M20-1239. doi: 10.7326/M20-1239.

9. Mohamad E, Azlan AA. COVID-19 and communication planning for health emergencies. Jurnal Komunikasi: Malaysian J Comm 2020; 36: 1-2.

10. Bao Y, Sun Y, Meng S, et al. 2019-nCoV epidemic: address mental health care to empower society. The Lancet 2020; 395: e37-e8. doi: 10.1016/S01406736(20)30309-3.

11. Shimizu K. 2019-nCoV, fake news, and racism. The Lancet 2020; 395: 685-6. DOI: 10.1016/S01406736(20)30357-3.

12. Brooks SK, Webster RK, Smith LE, et al. The psychological impact of quarantine and how to reduce it: rapid review of the evidence. The Lancet 2020; 395: 912-27. doi:10.1016/ S01406736(20)30460-8.

13. Öncü MA, Yýldýrým S, Bostancý $\mathrm{S}$, et al. The effect of COVID-19 pandemic on health management and health services: a case of Turkey. Duzce Medical Journal 2021;23(S1):61-70 doi: 10.18678/dtfd.860733.

14. Frisch AL, Camerini L, Diviani, N, et al. Defining and measuring health literacy: how can we profit from other literacy domains? Health Promot Int 2012;27: 117-26. doi: 10.1093/heapro/dar043.

15. Øimnáèová Z, Kajanová A, Bøízová B. Selected socio-economic factors of health literacy of the poor. Human Affairs 2018; 28: 461-70. doi:10.1515/ humaff-2018-003.7

16. Chesser AK, Woods KN, Smothers K, et al. Health literacy and older adults: a systematic review. Gerontol Geriatr Med 2016;2:1-13. doi: 10.1177/ 2333721416630492.

17. Mantwill S, Schulz PJ. Does acculturation narrow the health literacy gap between immigrants and non-immigrants - an explorative study Patient Educ Couns 2017;4:760-7 doi: 10.1016/ j.pec.2016.10.021.

18. Easton P, Entwistle VA, Wýllýams B. Health in the 'hidden population' of people with low literacy. A systematic review of the literature. BMC Public Health 2010;10:1-10 doi:10.1186/14712458-10-459. 
19. Van den Broucke S. Why health promotion matters to the COVID-19 pandemic, and vice versa. Health Promot Int 2020; 35: 181-6. doi:10.1093/heapro/daaa042.

20. Dadaczynski K, Okan O, Messer M, et al. Digital health literacy and web-based informationseeking behaviors of university students in Germany during the COVID-19 pandemic: crosssectional survey study. J Med Internet Res 2021;23; e24097. doi: 10.2196/24097.

21. Yabanova U, Özerbas DH. International student selection process in Turkey: characteristics, challenges and opportunities. Int J Progressive Educ 2020;16:137-56.

22. Republic of Turkey Ministry COVID-19 Information Page. General coronavirus table. Republic of Turkey Ministry of Health;2021.

23. Shaukat R, Naveed MA. Health literacy of university students in Covid-19 pandemic and infodemic: a Pakistani perspective. Library Philosophy Practice 2021;1-9.

24. Supriyati S, Angraeny DK, Carissa TM, et al. Preparing new normal: the health literacy assessment on the Covid-19. BKM J Comm Med Public Health 2021;37:27-32. https://doi.org/ 10.22146/bkm.63081.

25. Fauzi A, Husamah H, Miharja FJ, et al. Exploring COVID-19 literacy level among biology teacher candidates. Eurasia J Math Sci Technol Educ 2020;16:em1864. doi:10.29333/ejmste/8270.

26. Nguyen HT, Do BN, Pham KM, et al. Fear of COVID-19 scale - associations of its scores with health literacy and health-related behaviors among medical students. Inter J Environ Res Public Health 2020;17:4164. doi: 10.3390/ ijerph1711416427.

27. Salman M, Mustafa ZU, Asif N, et al. Knowledge, attitude and preventive practices related to COVID-19: a cross-sectional study in two Pakistani university populations. Drugs Ther Perspect 2020;36:319-25. doi: 10.1007/s40267-02000737-7.
28. Centers for Disease Control and Prevention. How to protect yourself \& others. Atlanta: Centers for Disease Control and Prevention;2021.

29. Sezer A, Kadýoðlu H. Development of adult health literacy scale. J Anatolia Nursing Health Sci 2014; 17:165-70.

30. Patil U, Kostareva U, Hadley M, et al. Health literacy, digital health literacy, and COVID-19 pandemic attitudes and behaviors in US college students: implications for interventions. Int J Environ Res Public Health 2021; 18:3301. https:// doi.org/10.3390/ijerph18063301.

31. Ikhlaq A, Hunniya BE, Riaz IB, et al. Awareness and attitude of undergraduate medical students towards 2019-novel corona virus. Pakistan J Med Sci 2020; 36(COVID19-S4), 32. doi: 10.12669/ pjms.36.COVID19-S4.2636.

32. Alzoubi H, Alnawaiseh N, Al-Mnayyis A, et al. COVID-19-knowledge, attitude and practice among medical and non-medical University students in Jordan. J Pure Appl Microbiol 2020; 14, 17-24. doi:10.22207/JPAM.14.1.04.

33. Cheng VCC, Wong SC, Chuang VWM, et al. The role of community-wide wearing of face mask for control of coronavirus disease 2019 (COVID-19) epidemic due to SARS-CoV-2. J Infect 2020;81:107-14. doi: 10.1016/j.jinf.2020.04.024.

34. Sentell T, Vamos S, Okan O. Interdisciplinary perspectives on health literacy research around the world: more important than ever in a time of COVID-19. Int J Environ Res Public Health 2020; 17:3010. doi: 10.3390/ijerph17093010.

35. Abel T, McQueen D. Critical health literacy and the COVID-19 crisis. Health Promot Int 2020 35:1612-3. DOI: 10.1093/heapro/daaa040.

36. Sun X, Shi Y, Zeng Q, et al. Determinants of health literacy and health behavior regarding infectious respiratory diseases: a pathway model. BMC Public Health 2013; 13: 261. DOI: 10.1186/14712458-13-261. 